\title{
Problems with the terminology proposed by Lavalli \& Lawton for certain life history phases of the American lobster Homarus americanus
}

\author{
S. L. Waddy*, D. E. Aiken \\ Aquaculture Division, Biological Station, Department of Fisheries and Oceans, 16 Lobster Lane, St. Andrews, New Brunswick E5B 2L9, Canada
}

In their tightly reasoned paper, 'Historical review of lobster life history terminology and proposed modifications to current schemes' (Crustaceana 69:594-609, 1996), Kari Lavalli and Peter Lawton proposed new terminology for several life history phases of the American lobster. For 2 of these phases-adolescent and adult - the proposed terminology is incompatible with current knowledge of the reproductive physiology of female American lobster and has the potential to adversely affect management decisions and the quality of size-at-maturity data obtained from the fisheries.

According to Lavalli \& Lawton (1996), onset of gonad maturation (oogenesis and spermatogenesis) distinguishes an immature juvenile from a physiologically mature adolescent. The physiologically mature adolescent, in turn, is considered a functionally mature adult once it is capable of forming pair bonds and mating successfully. By extension of this logic, a female lobster carrying a spermatophore in her seminal receptacle would be considered functionally mature and classified as an adult, irrespective of her reproductive potential. This terminology ignores 2 important biological facts.

Firstly, an adolescent female can, and often does, mate and accept the transfer of a spermatophore. The female then carries the spermatophore in its seminal receptacle - without spawning - until the next molt, when it is lost with the cast shell (Waddy \& Aiken 1991). Even females with completely immature (white) ovaries are occasionally found carrying stored sperm (Aiken \& Waddy 1980a, b, Waddy et al. 1995). Thus the presence of a spermatophore in the seminal receptacle is proof of the ability to mate successfully, but not proof of ability to spawn. Functional maturity of female

•E-mail: waddys@mar.dfo-mpo.gc.ca
American lobster should be related to ovarian development and the ability to spawn, not pair bond formation and mating. Although mating and reproduction are synonymous in male lobsters, females have not reproduced until they have spawned.

Secondly, physiological and functional maturity occur at the same body size in female American lobster. The ovary in a maturing lobster develops over an extended period that can span 2 or more intermolt periods (the prepubertal, pubertal, and Adult-I years of Aiken \& Waddy 1982), but once the oocytes mature (physiological maturity), the female spawns (functional maturity) without further somatic growth (Aiken \& Waddy 1982).

Lavalli \& Lawton (1996) do not provide a citation to justify a distinction between physiological and functional maturity in female American lobster, but in an earlier publication (Lawton \& Lavalli 1995) they erroneously cited Aiken \& Waddy (1980a) as relating physiological maturity to the presence of developed ovaries. The only references we are aware of to different states of maturity in female lobster are Ennis (1980, 1984), Dubé \& Grondin (1985) and Campbell (1989), but Lavalli \& Lawton (1996) cited none of these papers. The Campbell paper says simply, '... females reach physiological maturity (ovaries) at about 95-mm carapace length, and reach functional maturity (external eggs present) at 108-mm carapace length...' Although Campbell cites 2 of his earlier papers (Campbell 1983. Campbell \& Robinson 1983) as the source of this information, we have been unable to find these terms in either paper. Ennis (1984), working at the northern extreme of the geographic range for the American lobster, found that the high incidence of oocyte resorption in pre-spawning females caused a difference in the size at which females have mature ovaries (physiologi- 
cal maturity) and the size at which they spawn (functional maturity). When ovarian development is aborted just prior to spawning, many of the females will molt before becoming pre-ovigerous again, 1 to 2 yr after they were first in this condition. This apparent difference in the size at physiological and functional maturity is an artifact related to the high incidence of spawning failure in lobster living where seawater temperatures are marginal for reproduction. In most areas, there is a low incidence of oocyte resorption and physiological and functional maturity occur at the same size, a fact demonstrated by Dubé \& Grondin (1985) in the Magdalen Islands.

The important issue is not terminology but effective fishery management and stock conservation. Fishery biologists and resource managers in the United States and Canada attempt to manage the lobster fishery according to established conservation objectives (FRCC 1995, Chadwick 1999, NOAA 1999). One of those objectives is a significant increase in egg production. The egg-per-recruit model is an important tool in lobster fishery management, and size at maturity is a significant component of that model (FRCC 1995). If the Lavalli-Lawton definition of a functionally mature female (one that has mated) is adopted and applied in maturity assessments, it would result in sizeat-maturity estimates that are unrealistically low and estimates of reproductive potential that are unrealistically high. Neither would foster management decisions that would enhance egg production.

The Fisheries Resource Conservation Council (FRCC 1995) has emphasized the importance of reliable size at maturity estimates. Maturity in female American lobster has traditionally been based on the sizes of ovigerous lobster in the population, but this estimate is difficult because reproductive patterns vary geographically, only half the mature females become ovigerous in any one year, and ovigerous females may not be accurately represented in the catch (Campbell \& Pezzack 1986, Waddy et al. 1995). It is desirable, therefore, to enhance size-at-maturity determinations by including other criteria. In our opinion, the only reliable indicators of maturity in non-ovigerous American lobster are the presence of (1) mature ovaries (Stages $4 \mathrm{~b}, 5$ and 6), (2) yellow oviducts, and (3) well-developed cement glands. All of these indicate that female lobster have spawned in the past or that spawning is imminent. The criteria for these are published and straightforward (Aiken \& Waddy 1980a, b, 1982, Waddy et al. 1995).

\section{LITERATURE CITED}

Aiken DE, Waddy SL (1980a) Reproductive biology. In: Cobb JS, Phillips BF (eds) The biology and management of lobsters, Vol 1. Academic Press, New York, p 215-276

Aiken DE, Waddy SL (1980b) Maturity and reproduction in the American lobster. Can Tech Rep Fish Aquat Sci 932: $59-71$

Aiken DE, Waddy SL (1982) Cement gland development, ovary maturation, and reproductive cycles in the American lobster Homarus americanus. J Crust Biol 2:315-327

Campbell A (1983) Growth of tagged American lobsters, Homarus americanus, in the Bay of Fundy. Can J Fish Aquat Sci 40:1667-1675

Campbell A (1989) The lobster fishery of southwestern Nova Scotia and the Bay of Fundy. In: Caddy JF (ed) Marine invertebrate fisheries: their assessment and management. John Wiley \& Sons, New York, p 141-158

Campbell A, Pezzack DG (1986) Relative egg production and abundance of berried lobsters, Homarus americanus, in the Bay of Fundy and ofí southwestern Nova Scotia. Can $\mathbf{j}$ Fish Aquat Sci 43:2190-2196

Campbell A, Robinson DG (1983) Reproductive potential of three lobster (Homarus americanus) stocks in the Canadian Maritimes. Can J Fish Aquat Sci 40:1958-1967

Chadwick $M$ (1999) Is the lobster fishery going to pot? TIME 154(16): $26-27$

Dubé P, Grondin P (1985) Maturité sexuelle du homard (Homarus americanus) femelle aux lles-de-la-Madeleine. Canadian Atlantic Fisheries Scientific Advisory Document $85 / 85$

Ennis GP (1980) Size-maturity relationships and related observations in Newfoundland populations of the lobster (Homarus americanus). Can J Fish Aquat Sci 37:945-956

Ennis GP (1984) Comparison of physiological and functional size-maturity relationships in two Newfoundland populations of lobsters Homarus americanus. Fish Bull (Wash, DC) $82: 244-249$

FRCC (Fisheries Resource Conservation Council) (1995) A conservation framework for Atlantic lobster. Report to the Minister of Fisheries and Oceans FRCC95.R.1, November 1995. Minister of Supply and Services Canada, Ottawa

Lavalli KL, Lawton P (1996) Historical review of lobster life history terminology and proposed modifications to current schemes. Crustaceana 69:594-609

Lawton P, Lavalli KL (1995) Postlarval, juvenile and adult ecology. In: Factor JR (ed) The biology of the lobster Homarus americanus. Academic Press, San Diego, p 47-88

NOAA (National Oceanic \& Atmospheric Administration) (1999) Our living oceans. Report on the Status of US Living Marine Resources 1999. US Dept Comm NOAA/NMFS/ Office of Science and Technology, Silver Springs

Waddy SL, Aiken DE (1991) Mating and insemination in the American lobster, Homarus americanus. In: Bauer RT, Martin JW (eds) Crustacean sexual biology. Columbia University Press, New York, p 126-144

Waddy SL, Aiken DE, de Kleijn DPV (1995) Control of growth and reproduction. In: Factor JR (ed) The biology of the lobster Homarus americanus. Academic Press, San Diego, p 217-266 